\title{
KINERJA KAMERA DIGITAL REFLEKS LENSA TUNGGAL DENGAN SISTEM FOUR THIRDS
}

\author{
Hendrie Hartono \\ Jurusan Desain Komunikasi Visual, Fakultas Komunikasi dan Multimedia, BINUS University \\ Jln. K.H. Syahdan No. 9, Kemanggisan, Jakarta Barat 11480 \\ rocknroll_swindle@yahoo.com
}

\begin{abstract}
The core design concept of the 4/3 (Four Thirds) system is to facilitate optimization of the size, performance, of digital cameras and lenses. In addition, a standardized lens mount allows photographers to freely combine interchangeable lenses and cameras from different manufacturers. This is the key feature of the Four Thirds system, the one that makes it possible to explore the full potential of digital photography. The purpose of this research to give description and knowledge about the existence of a new system in digital photography. In the end, this article will be helpful to find out the benefits and disadvantages in using this system and also as comparison with other systems in digital photography.
\end{abstract}

Keywords: digital camera, photography, four thirds

\begin{abstract}
ABSTRAK
Konsep inti dari desain sistem 4/3 (four thirds) adalah untuk memberikan fasilitas kinerja, ukuran dari kamera digital dan lensa yang lebih optimal. Selain itu, standarisasi mounting lensa memungkinkan fotografer untuk bebas menggabungkan, menukar lensa kamera dari produsen yang berbeda. Ini adalah fasilitas dari sistem four thirds, salah satu yang memungkinkan untuk mengeksplorasi potensi penuh dari fotografi digital. Tujuan tulisan ini adalah untuk memberikan gambaran dan pengetahuan tentang munculnya sebuah sistem yang baru dalam dunia fotografi digital. Pada akhirnya, artikel ini akan membantu mengetahui apa kelebihan dan kekurangan dari penggunaan sistem ini dan juga perbandingannya dengan sistem lain yang sudah terlebih dahulu muncul dalam dunia digital fotografi.
\end{abstract}

Kata kunci: kamera digital, fotografi digital, four thirds 


\section{PENDAHULUAN}

Banyak hal yang mempengaruhi kinerja sebuah kamera digital,karena kualitas gambar tidak tergantung lagi pada beberapa aspek sederhana seperti pada penggunaan film (Soekojo, 2010). Dalam perkembangan teknologi di era digital saat ini telah mengubah dunia fotografi, yang tadinya menggunakan media film menjadi media digital yang serba praktis, seperti contoh nya kita tidak perlu khawatir jika foto yang kita ambil akan gagal,karena praktis foto dalam kamera digital bisa kita hapus dan dilihat sesuka hati tanpa memikirkan proses dan biaya cetak seperti pada jaman penggunaan kamera film.kamera digital menjadi sebuah revolusi besar dalam dunia fotografi dan menjadi sebuah kegiatan yang menyenangkan. Oleh karena itu mau tidak mau para produsen kamera pun merubah jajaran kamera nya menjadi kamera digital,mulai dari kamera pocket atau compact dan kamera refleks lensa tunggal (single lens reflex).meskipun masih ada sebagian orang yang bertahan dengan kamera film, perlahan tapi pasti penggunaan kamera film sudah mulai ditinggalkan.

Pada awal perkembangan era digital,produsen kamera kelas atas seperti Canon dan Nikon tidak langsung membuat kamera digital SLR (single lens reflex), mereka membuat kamera DSLR dengan bentuk yang memiliki lensa mount sama dengan lensa mount pada kamera film. Artinya, secara teknis, produsen kamera analog hanya mengganti penggunaan film dengan sensor digital dan menyamakan ukuran sensor film 35mm untuk di aplikasikan menjadi sensor digital yang sering di sebut dengan sensor full frame, Sedangkan lensa dan teknologi lainnya dapat dikatakan hampir sama. Sistem Four Thirds muncul dengan konsep 100\% digital, sistem kamera baru yang benar benar berbeda dengan kamera film, baik dari teknologi kamera maupun lensa lensanya, sistem ini di prakarsai oleh salah satu produsen kamera yaitu Olympus, yang kemudian didukung oleh beberapa produsen kamera lainnya seperti Kodak, Panasonic, Leica, Sigma, Fuji, dan Sanyo.

Tujuan tulisan ini adalah untuk memberikan gambaran dan pengetahuan tentang munculnya sebuah sistem yang baru dalam dunia fotografi digital. Hal ini dikhusukan agar pilihan semakin banyak dalam sebuah sistem fotografi digital serta untuk mengetahui apa kelebihan dan kekurangan dari penggunaan sistem ini dan juga perbandingannya dengan sistem lain yang sudah terlebih dahulu muncul dalam dunia digital fotografi.

\section{METODE}

Metode penelitian yang dilakukan dalam membuat pembahasan jurnal ini, yaitu metode pencarian data (survei) atau metode pustaka, metode obeservasi sistem dan produk dan serta metode pengujian langsung dan perbandingan antara masing masing kekurangan dan kelebihan dari beberapa sistem kamera digital.

Metode pencarian data yang dilakukan oleh penulis adalah dengan pencarian dari beberapa buku tentang kamera digital sistem four thirds yang ditulis oleh beberapa fotografer profesional serta menggabungkan dengan teori konsep digital dan beberapa artikel dan data serta statistik resmi mengenai kamera digital sistem four thirds.

Untuk metode observasi sistem dan produk, penulis melakukan pencarian beberapa test sistem dan produk dari beberapa web pengujian produk digital fotografi untuk mengetahui spesifikasi dari beberapa produk yang akan di uji, serta pengujian produk langsung dari berbagai sumber dan penulis sendiri, dengan spesifikasi yang sama dari produk dengan sistem sensor yang berbeda.Sehingga kita bisa melihat langsung kinerja dan perbandingan nya, dan kelebihan serta kekurangan dari sistem ini secara menyeluruh. 


\section{HASIL DAN PEMBAHASAN}

Jika dilihat sepintas,antara satu kamera digital refleks lensa tunggal (DLSR) satu dengan yang lain seperti nya sama saja,ukuran satu dengan yang lain juga tidak terlalu banyak berbeda,tetapi mengapa terdapat perbedaan kualitas tampilan warna gambar antara satu kamera dengan kamera lainnya.

Banyak hal yang bisa mempengaruhi kinerja sebuah kamera digital,karena kualitas gambar tidak tergantung lagi pada beberapa aspek sederhana seperti pada masa penggunaan film,konsentrasi kita bertumpu terutama pada karakter dan kemampuan film,pada sistem digital kita menghadapi banyak sekali aspek teknis yang mempengaruhi kualitas pembentukan gambar,baik oleh kamera juga penyempurnaan gambar di komputer.

Untuk membahas lebih dalam tentang kamera digital refleks lensa tunggal dengan sistem four thirds, perlu ada penjelasan mengenai beberapa faktor pembentukan gambar pada kamera digital,salah satu nya adalah sensor kamera digital yang berfungsi untuk menangkap cahaya dalam bentuk sinyal listrik dan merubahnya menjadi data digital.Ada banyak faktor teknis ada sensor salah satunya adalah panel ukuran sensor,panel ukuran sensor pun ada beberapa jenis,yaitu full frame, APS dan four thirds, dan sebagainya, tipe sensornya pun bermacam macam dari CCD,CMOS, dan LiveMOS.

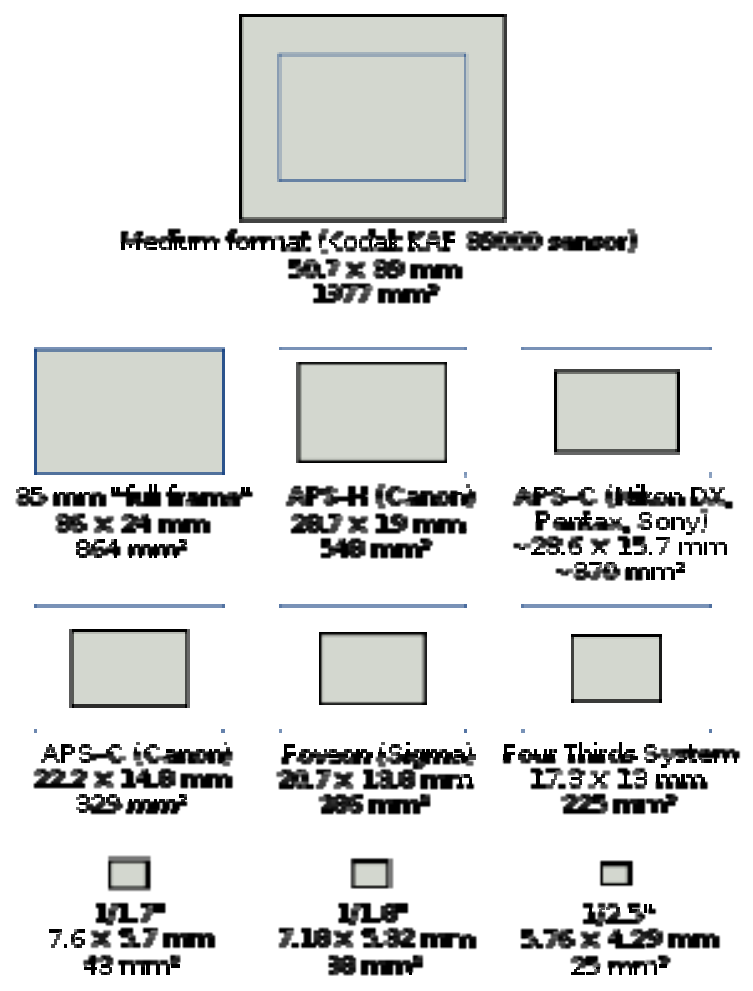

Gambar 1 Jenis-jenis sensor berdasarkan ukuran

Dalam Gambar 1, ukuran sensor diatas,ukuran sensor terbesar dimiliki oleh sensor medium format yang berukuran $50.7 \times 39 \mathrm{~mm}$, kamera yang memiliki ukuran sensor medium format biasanya memiliki harga jual yang sangat mahal,akibat nya tidak banyak orang yang memiliki nya, ukuran sensor yang biasa dipakai untuk kamera DSLR adalah sensor full frame yang memiliki ukuran 36x24mm atau sering juga disebut sensor 35mm,sensor yang di sejak media film. 
Untuk kamera DLSR kelas non-profesional,karena alasan biaya,biasanya produsen kamera menempatkan sensor yang sedikit lebih kecil dari sensor Full Frame yang biasa di sebut sensor APS (Advanced Photo System), sensor APS sendiri memiliki ukuran yang berbeda beda dari tiap produsen,seperti produsen kamera merek Canon yang memiliki sensor APS sebesar 28.7x19mm (APS-H) dan 22.2x14.8mm (APS-C), sedangkan untuk produsen kamera merek Nikon, Pentax, dan Sony memiliki sensor APS dengan ukuran 23.6x15.7mm (APS-C).

Sensor four thirds system memperkecil ukuran diameter sensor lebih kecil dari APS dan kurang lebih setengah dari sensor 35mm full frame, tetapi sensor four thrids system adalah sensor baru, tipe sensor yang berbeda dari produsen kamera full frame, sensor ini disebut dengan sensor LiveMos.sensor ini mereduksi sisi wide angle, memperpendek jarak fokus lensa sampei setengah dari panel sensor (sensor lebih meju mendekati lensa) dan merapatkan pixel, sehingga detil gambar yang didapat tinggi, secara teknis proyeksi gambar pada sensor four thirds sama dengan gambar pada panel film.

Banyak orang menyangka bahwa sensor ukuran 4/3 atau four thirds adalah sensor hasil pemotongan setengah dari full frame, sehingga menyebabkan adanya crop factor dua kali, padahal sebenarnya yang terjadi adalah bukan crop factor seperti pada sensor APS,tetapi adalah faktor kesetaraan atau equivalent dengan sensor $35 \mathrm{~mm}$, jadi apabila kita membidik objek dalam jarak pandang yang sama,kamera berformat four thirds membutuhkan lensa berjarak pandang 300 $\mathrm{mm}$, maka di kamera berformat $35 \mathrm{~mm}$ membutuhkan lensa berjarak pandang $600 \mathrm{~mm}$.oleh karena itu biasanya dalam pembahasan lensa untuk format four thirds selalu di cantumkan faktor kesetaraan jarak pandang terhadap lensa untuk format 35mm. Demikian juga berlaku untuk lensa lainnya.

Nama sistem berasal dari ukuran gambar sensor yang digunakan dalam kamera, yang umumnya disebut sebagai 4/3 tipe atau 4/3 jenis sensor, dan memiliki sistem diameter gambar 4:3,meski dalam penggunaan nya pun, kamera four thirds pun difasilitasi dengan pengambilan gambar format 3:2. Aspek rasio sensor memiliki dampak pada desain lensa. Sebagai contoh, lensa yang dirancang oleh Olympus untuk four thirds berisi empat persegi panjang internal atau permanen terpasang kelopak yang mengoptimalkan operasi mereka untuk rasio aspek 4:3.

Masalah terbesar yang dihadapi oleh kamera DSLR adalah penurunan kualitas gambar dan sisi pinggiran yang gelap (viginete) dan munculnya flare, chromatic aberration, flare dihasilkan ketika cahaya yang dipantulkan pada permukaan sensor gambar tercermin lagi pada permukaan lensa. Gambar di bawah ini akan menjelaskan perbedaan pengambilan gambar antara kamera DLSR format $35 \mathrm{~mm}$.

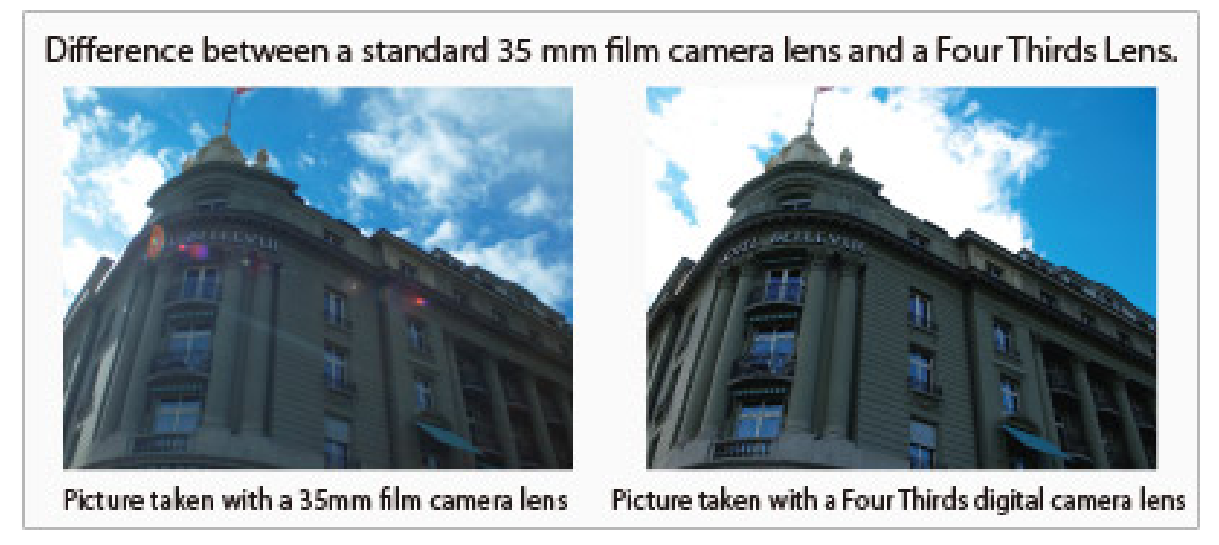

Gambar 2 Perbandingan Percobaan dan Efeknya dapat Berbeda sesuai dengan Kondisi Sumber: Olympus Imaging Corp. (2011) 
Kedua foto di atas diambil dengan menggunakan sudut pandang yang sama dan F (diafragma) yang sama, yang lain diambil menggunakan lensa $35 \mathrm{~mm}$ film standar kamera dan yang lainnya dengan lensa four thirds. Suatu perbandingan dari gambar jelas menunjukkan flare dan ghosting pada gambar yang diambil dengan lensa kamera film 35mm, serta viginette di sekitar pinggiran dan kurangnya ketajaman secara keseluruhan. Sedangkan gambar yang diambil dengan lensa four thirds, di sisi lain, tidak memiliki flare atau ghosting dan tajam merata di seluruh bidang gambar.
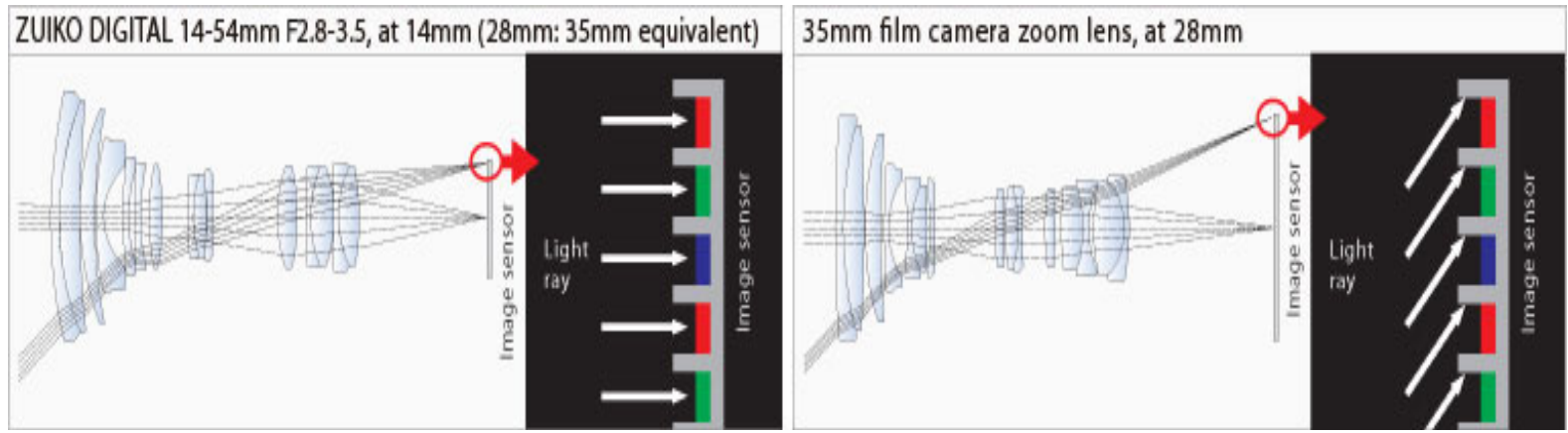

Gambar 3 Perbedaan Arah Jatuhnya Cahaya yang Masuk pada Sensor Kamera 4/3 dan Sensor 35mm Sumber: Olympus Imaging Corp. (2011)

Pada kamera refleks lensa tunggal di era digital ini (DSLR) yang menggunakan sensor gambar sebesar 35mm (full frame) dan menggunakan lensa film (lensa yang masih bisa digunakan untuk kamera film 35mm), secara fisik kelihatannya tidak masalah. Tetapi sebenarnya, terdapat perbedaan struktur dan karakter kerja sensor gambar digital saat menerima cahaya membuat lensa film tidak bisa bekerja optimal untuk sistem digital.

Film bisa diberi pencahayaan dengan cahaya dari berbagai arah, baik lurus maupun miring,maka lensa desain film 35mm cahaya nya jatuh membentuk sudut pada pinggir dan pojok bingkai film. Sebaliknya sensor gambar kamera digital yang terdiri dari pixel atau Photodiodes yang dilindungi sungkup,hanya bisa menerima cahaya secara efektif jika cahaya datang dengan arah tegak lurus ke arah panel sensor gambar.

Karena kamera refleks lensa tunggal sudah digitalisasi. Maka posisi film digantikan oleh panel sensor gambar digital, akibatnya sensor gambar hanya mampu mengangkap cahaya secara efektif jika cahaya yang datang jatuhnya tegak lurus ke arah bidang gambar.Jika lensa kamera refleks tunggal film digunakan untuk kamera lensa refleks tunggal digital (DSLR) maka cahaya proyeksi lensa jatuh dengan sudut miring pada bagian pinggir dan pojok bingkai sensor.

Akibatnya, cahaya yang jatuh pada pingghir dan pojok sensor tersebut dapat berakibat turun nya kecerahan gambar dan proyeksi kecerahan gambar pun akan memburuk di bagian pojok gambar dengan penurunan kualiatas ketajaman dan warna bahkan bisa menjadi gelap pada pojok gambar atau yang sering di sebut dengan viginete. Masalah ini akan menjadi lebih buruk lagi pada penggunaan lensa sudut lebar (wide angle lens).

Supaya mendapatkan proyeksi cahaya yang efektif dari lensa menuju sensor kamera maka ukuran panel sensor kamera harus dibuat lebih kecil dari ukuran bingkai sensor film.akibat nya sisi wide angle tereduksi karena ruang pandang menjadi lebih sempit dan panjang titik fokus lensa sudah tidak efektif lagi dan kita sudah tidak bisa lagi menggunakan lensa lensa kamera film pada kemampuan optimalnya. 
Lensa untuk kamera digital harus dirancang secara khusus,agar mampu memberikan cahaya secara efektif dan tegak lurus ke panel sensor, bukan hanya ke bagian tengah gambar, tetapi sampai pada ke sudut gambar. Oleh karena itu, beberapa produsen yang ber kerjasama membentuk sistem four thirds pun membat lensa baru untuk format digital yang tidak lagi kompatibel untuk media film.
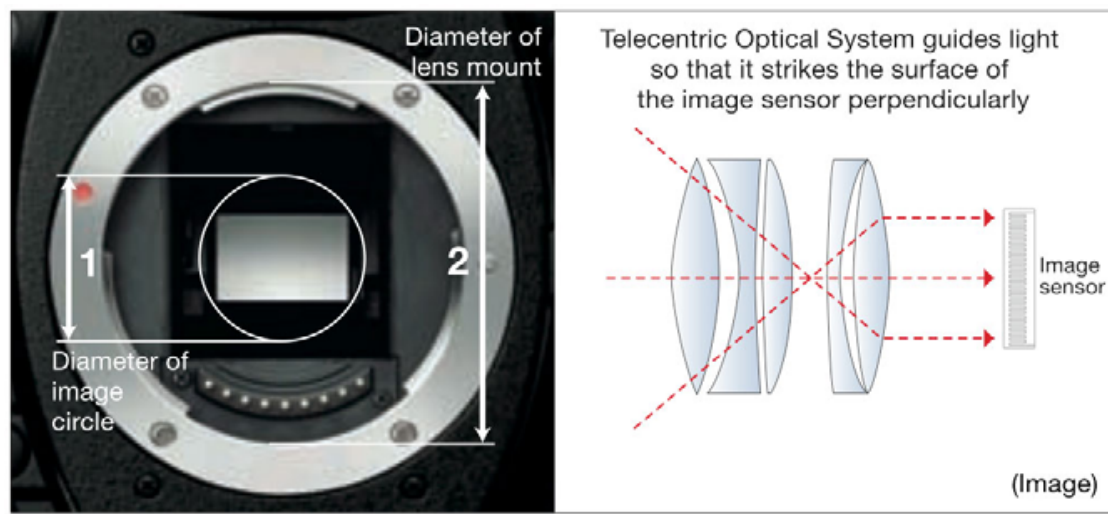

Gambar 4 Ukuran Diameter dari Sensor 4/3 dan Diameter Mounting Lensa Sumber: Olympus Imaging Corp. (2011)

\section{Kelebihan Kamera Digital dengan sistem Four Thirds}

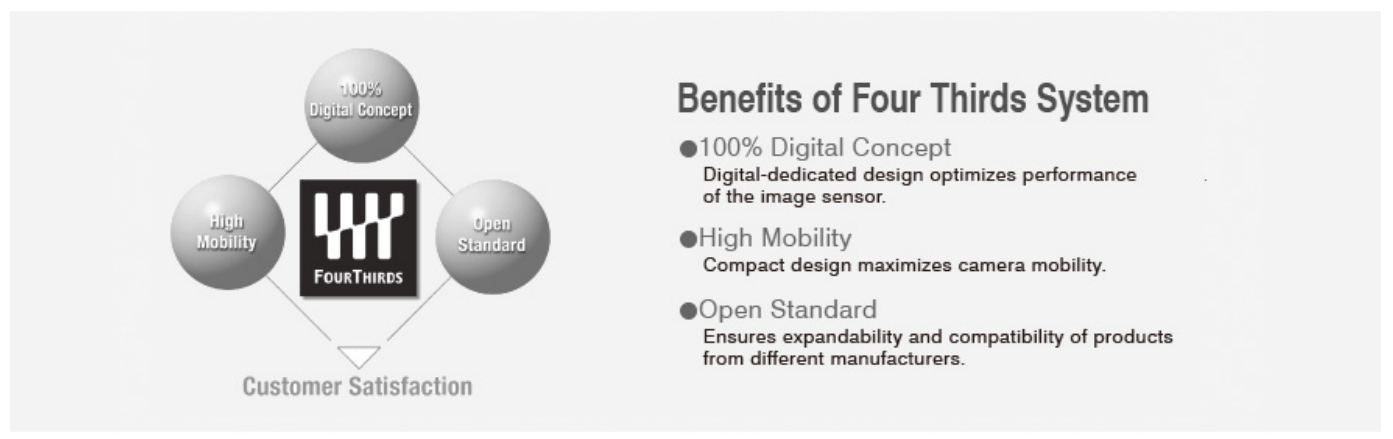

Gambar 5 Kelebihan Sistem Four Third

Sumber: Olympus Imaging Corp. (2011)

Berdasarkan Gambar 5, kelebihan kamera digital dengan sistem four thirds adalah: (1) 100\% digital concept, four third system adalah kamera digital yang benar-benar baru, bukan pengembangan dari kamera analog yang sudah ada. Dengan demikian performa sensor digitalnya dapat bekerja secara optimal; (2) ukuran sensor yang lebih kecil membuat badan kamera bisa dibuat lebih kecil dan ringan.Lensa pun dapat di buat dengan ukuran yang lebih kecil dan ringkas; (3) dengan diperkecilnya ukurang sensor juga dapat membuat lubang lensa yang lebih kecil,keuntungan nya adalah, sistem ini memungkinkan untuk membuat lensa zoom dengan bukaan terkecil f/2.0, serta membuat lensa telephoto yang mempunyai bukaan terkecil f/2.8; (4) kamera dan lensa yang mengadopsi four third system dapat saling bertukar kamera dan lensa. Contoh nya, lensa Panasonic (Leica) dapat dipasangkan pada Olympus. Sigma hanya perlu membuat satu tipe lensa yang dapat digunakan pada Panasonic/Leica dan Olympus; dan (5) ruang cahaya yang lebih efektif, secara fisik film analog dan sensor digital sangat berbeda dalam menerima cahaya. Film terdiri dari jutaan butir perak. Cahaya yang masuk dari lensa analog meskipun tidak tegak lurus masih dapat diterima dengan baik oleh butiran-butiran tadi.Sedangkan sensor digital terdiri dari lubang-lubang photosensor berupa titik-titik 
yang disebut pixel. Akibatnya, diperlukan sumber cahaya yang tegak lurus dengan sensor untuk mendapatkan intensitas cahaya yang merata, ketajaman dan detail yang tinggi,warna yang cerah dan akurat

\section{Kekurangan Kamera Digital dengan Sistem Four Thirds}

Kekurangan kamera digital dengan sistem four thirds adalah: (1) karena sensor berukuran kecil,maka resolusi gambar (megapixel) tidak bisa sebesar pada kamera bersensor 35mm; (2) ukuran sensor yang lebih kecil membuat noise menjadi lebih tinggi,ini juga bisa disebabkan karena kerapatan pixel yang tinggi; (3) dengan faktor kesetaraan membuat bukaan diafragma menjadi dua kali lebih tipis dibanding sistem lain; (4) four thirds adalah sistem yang tergolong baru dalam dunia fotografi, oleh karena itu,pemakai nya pun tidak sebanyak sistem kamera full frame atau APS, yang mengakibatkan sedikit lebih sulit untuk mencari komunitas yang besar atau aksesoris dari produk tersebut,serta minim nya pembuatan lensa dan aksesoris dari pihak ke tiga, sehingga pilihan pun menjadi terbatas.

Produsen Kamera yang mendukung sistem four thirds yaitu Olympus, Panasonic, Leica, Sigma, Fuji, Kodak dan Sanyo. Tetapi, hanya Leica, Olympus dan Panasonic yang memiliki Badan Kamera berformat four thirds. Produsen lainnya hanya mendukung sensor dan lensa, seperti Sigma yang membuat lensa pihak ketiga untuk mendukung sistem ini, Leica membuat lensa untuk Panasonic Limix, Kodak yang menjual sensornya ke Olympus, meskipun saat ini Olympus berpindah memakai sensor buatan Panasonic.

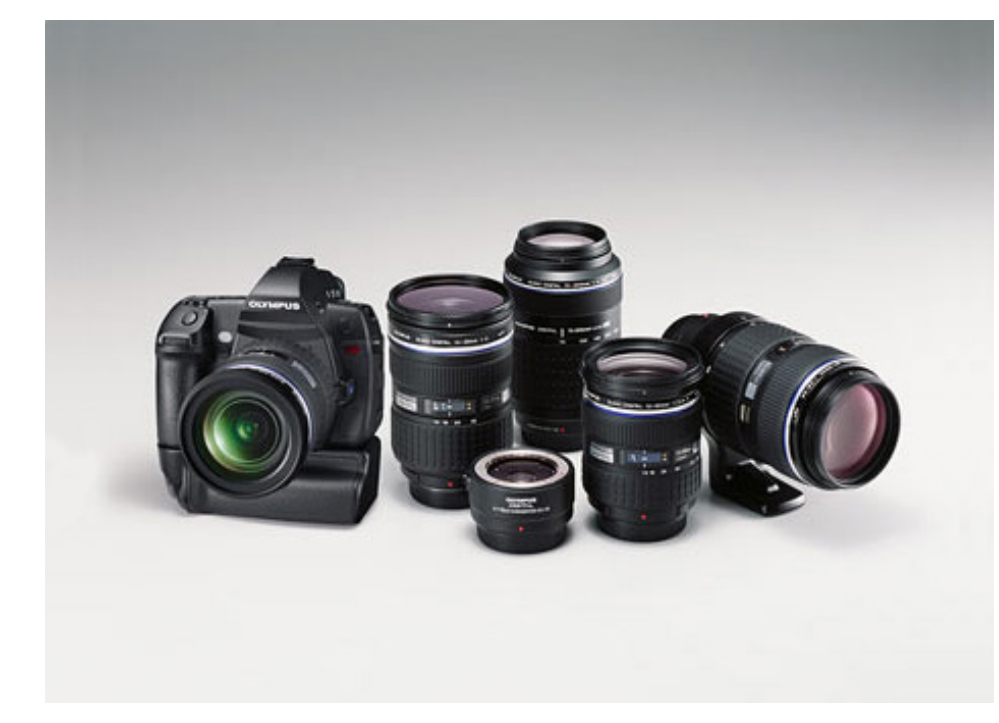

Gambar 6 Contoh Produk Kamera dan Lensa dengan Sistem Four Thirds dari Produsen Kamera Olympus

Sumber: Jurrien (2007)

\section{PENUTUP}

Dalam perkembangan nya memang terdapat perbedaan mendasar antara fotografi di era analog atau era film dengan era digital, dalam era digital dimana segala nya lebih di mudah kan dan segala nya di kendalikan oleh mesin, sebaiknya memang dibutuhkan pilihan yang bijak dalam menentukan sebuah sistem yang dipiliih sesuai dengan kebutuhan masing masing individu. Sistem Four Thirds hadir untuk memenuhi dan ikut meramaikan pasar fotografi digital dengan konsep yang baru,Dengan mengetahui serta memahami sistem kamera Four Thirds, maka masyarakat mempunya banyak pilihan 
sistem dalam panduan untuk memilih serta membeli kamera digital lensa refleks tunggal (DSLR) sesuai dengan kelebihan dan kekurangan dari masing masing sistem dan juga kebutuhan dari masing masing calon pengguna serta para pengguna yang ingin memahami sistem lain dari fotografi digital. Dalam dunia fotografi digital, sebuah sistem memang cukup memegang peranan penting, dan para fotografer yang akan atau yang sudah menjalani dunia fotografi digital sebaiknya mengetahui berbagai macam sistem dan fasilitas yang di tawarkan oleh produsen kamera, tetapi tetap pada prinsipnya sistem hanyalah sebuah alat, sebuah media yang dapat membantu kita mengerjakan sesuatu, dalam hal ini fotografi,tetap kembali kepada masing masing individu,karena sebenarnya sebuah sistem kamera apaapun bisa membuat karya fotografi yang indah.

\section{DAFTAR PUSTAKA}

Jurrien, R. (2007). Olympus Zuiko digital lenses. Diakses dari http://www.pmashow.com/0151/olympus/slrlens/zuiko digital lenses/

Olympus Imaging Corp. (2011). Benefit of Four Thirds, Diunduh dari http://www.fourthirds.org/en/fourthirds/index.html

Soekojo, M. (2010). Digital underwater photography. Jakarta: Nugra Indimedia Adika. 